\title{
UN PUENTE ENTRE SUJETO Y OBJETO el humor en la poesía de José Watanabe
}

\author{
JUAN RYUSUKE ISHIKAWA \\ California State University, Fullerton
}

Un cauteloso observador de la naturaleza, José Watanabe, poeta peruano, publica su primer poemario Álbum de familia en 1971. Posteriormente, después de un periodo de 18 años de silencio, en 1989 publica el Huso de la palabra; a partir del cual se vuelve más prolífera su producción. Por ejemplo, publica: Historia natural en 1994, Cosas del cuerpo en 1999, Antígona en 2000, Habitó entre nosotros en 2002, Lo que queda en 2005, La piedra alada en 2005, Banderas detrás de la niebla en 2006 y el guion para la versión fílmica de La ciudad y los perros en 1985, dirigida por Francisco Lombardi. También contribuyó en un libro de historia sobre japoneses en Perú titulado La memoria del ojo de 1999 junto con Oscar Chambi y Amelia Morimoto. Tras su fallecimiento el 25 de abril de 2007, nos deja un legado de poemas que, con suma simplicidad, gran ternura y profundas reflexiones sobre la condición humana, el mundo que le rodea y el sentido de la vida, acentúan la importancia de la observación como condición primaria para la creación poética de Watanabe.

Según la crítica, a José Watanabe se le considera como parte de la Generación de los 70s del Perú —especialmente del grupo «Hora Zero»-, pero más por los años en los le toca vivir y crear que por las características de su producción, ya que no son poemas comprometidos, ni se ambientan en la urbe. Los poemas de Watanabe son únicos en el sentido de que la mayoría se ubican en espacios rurales o campestres, y no tienen como eje principal la cuestión sociopolítica. Sus poemas más bien se caracterizan por temas como: la naturaleza, la nostalgia 
por la niñez, la muerte, los animales, la familia, el cuerpo, el espacio rural, los límites de la palabra (la poesía) y la percepción (el ver).

No cabe duda que el elemento que resalta en la poética de Watanabe es la percepción. El ojo es el que capta y recorta escenas de la naturaleza, el recuerdo y las experiencias personales, y de ahí, sus poemas nos invitan a una reflexión profunda. Percy Galindo en su artículo titulado «La integración del yo en la naturaleza en Cosas del cuerpo de José Watanabe» menciona que:

[e]l universo poético de este autor ha recibido laudatorios comentarios y artículos fragmentarios que han brindado sugestiones interesantes sobre su relación con el haiku japonés, sus temas recurrentes, la economía de sus recursos, su esencialismo ideológico, su sincretismo vivencial, etc. ${ }^{1}$

Asimismo, señala que:

[...] una de las características primordiales de la poética de Watanabe [es]: las diversas estrategias con que los locutores de sus poemas asumen sus discursos para establecer un vínculo con la naturaleza a través de la acción perceptiva².

Establece, de esta forma, un vínculo con la tradición del haiku y la naturaleza, así como la percepción de ésta. El elemento que sobresale en la poesía de Watanabe es su manera de aproximarse a la naturaleza por medio de una herramienta principal que es el ojo y de ahí hace que ese espacio mínimo e íntimo entre objeto y sujeto, cobre vida. Al final, las imágenes se filtran para crear una impresión que incita a un pensamiento profundo; casi meditativo. Aun cuando el formato no sigue en absoluto el haiku, la aproximación hacia la materia poética sí vislumbra su indudable marca.

En una entrevista con Rebeca Tsurumi, Watanabe afirma que se considera peruano con una herencia japonesa ${ }^{3}$. En efecto, una de las grandes influencias en su trayectoria literaria ha sido su padre que le recitaba haikus y le mostraba libros de grandes pintores clásicos nipones. En algunos de sus poemas aparecen haikus — de Basho, Issa y Moritake, por ejemplo - lo cual indica que conocía y apreciaba dicha tradición poética japonesa. Como se mencionó anteriormente, el elemento que resalta en gran parte de la poesía de Watanabe es producto de la estética del haiku que consiste en su posicionamiento frente al objeto y su capacidad de evocar ideas, reflexiones y sentimientos de él sin

${ }^{1}$ P. Galindo, «La integración del yo en la naturaleza en Cosas del cuerpo de José Watanabe», Espéculo, 24, 2003. <http://www.ucm.es/info/especulo/numero24/watanabe.html> [Consulta: 3 de enero de 2017].

2 P. Galindo, loc. cit. [Consulta: 3 de enero de 2017].

3 Véase R. Tsurumi, The Closed Hand: Images of the Japanese in Modern Peruvian Literature, Purdue University Press, West Lafayette, 2012, págs. 240-244.

${ }^{4} \mathrm{Me}$ refiero a los poemas «Imitación de Matsuo Basho», «En el cauce vacío» y «Casa joven con dos muertos», respectivamente. 
tener que manifestarlo abiertamente. Es decir, se puede ver una sutil muestra de una estética y perspectiva japonesa. No obstante, la reconocible influencia del haiku y lo que le inculca su padre en torno a la cultura japonesa, coincido con lo que indica Ignacio López-Calvo al afirmar en su libro The Affinity of the Eye: Writing Nikkei in Peru que tal vez la crítica se haya enfocado demasiado en «lo japonés» del poeta. Aunque sí es evidente que hay una marcada influencia del haiku, como indica López-Calvo, especialmente en torno a la percepción de las cosas, el aproximarse al objeto sin metáforas, y la notable cosmovisión budista presente en muchos de sus poemas donde el sujeto poético —el ser humano- se ve ante la naturaleza y hay un intento por integrarse a ella o de acercarse a ella ${ }^{5}$, es importante señalar que hay otras maneras de entender la poesía de Watanabe. Esto es, verlo como un poeta que ha logrado colocarse como uno de los más grandes poetas contemporáneos de Hispanoamérica.

Ahora bien, para este artículo en particular, lo que interesa es primero, hacer un análisis de la poesía de José Watanabe no desde el punto de vista de su etnicidad, sino más bien enfocándome en su poesía misma. Es decir, se dejará a un lado el hecho de que se trate de un poeta descendiente de japoneses, $y$ más bien se leerán sus poemas en base a teorías occidentales sobre el humor. Pos-teriormente, partiendo de este tema del humor y la sátira como marco analítico, se analizarán tres poemas en específico — «La mantis religiosa», «Fábula» $\mathrm{y}$ «El camello»— que tienen como elemento en común el enfoque en animales e insectos. Aquí se pretende ver qué tipo de relación se establece entre el sujeto poético y el objeto que pertenece al mundo animal, así como la importancia del humor en esta relación. Finalmente, se verán estos tres poemas para establecer una conexión entre el uso del humor y los temas constantes en la poesía de Watanabe como: el ser humano ante la naturaleza; los límites de la palabra ante lo que uno ve; y finalmente, una reflexión sobre la condición del ser humano y su aproximación al sentido de la vida, que en el caso de estos poemas, se percibe como un ser diminuto ante las leyes de la naturaleza.

La semilla de este ensayo se encuentra en un pasaje de un artículo del crítico peruano Víctor Vich titulado «El materialismo <real $>$ de José Watanabe» donde menciona que en la poesía de Watanabe se nos muestra cómo lo humano se encuentra atrapado en las redes del lenguaje o la metáfora:

[...] la condición del poeta es representar lo irrepresentable, ... la causa del deseo, aquellas formas o significados que se están desvaneciendo. A pesar de lo inútil de dicha tarea, a pesar de no poder nombrar lo innombrable, la poesía se propone a insistir una y otra vez en lo mismo: no importa que el hielo se derrita y que las palabras no alcancen, sólo importa estar ahí apuntando hacia dicho objetivo ${ }^{6}$.

5 I. López-Calvo, The Affinity of the Eye: Writing Nikkei in Peru, The University of Arizona Press, Tucsón, 2013, pág. 173.

${ }^{6}$ V. Vich, «El materialismo <real > de José Watanabe», Iberoamericana, X, 37, 2010, 119-134, pág. 133. 
Es por eso que, según el análisis de Vich sobre la poesía de Watanabe, siempre hay algo en la naturaleza que se trata de captar por la palabra o el ojo, pero que se queda fuera. Por ende, la poesía sirve para señalar aquello que no se puede describir. En Watanabe, la naturaleza es algo que supera el nivel de lenguaje, pero puede abarcarse a nivel de experiencia. No obstante, tiene que haber algo que sirva como puente entre el orden simbólico y lo «Real» —-según lo define Lacan- que señale qué es aquello que queda fuera del «discurso». Es por esto mismo que un enfoque en el concepto del humor podría servir como una posibilidad. Este artículo, por lo tanto, se propone a explorar este tema.

Las ideas del filósofo inglés Simon Critchley en su texto On Humor servirán como referencia teórica. En este texto, Critchley analiza el significado y la importancia del humor. Según Critchley, hay tres teorías en torno al humor: «La teoría de la superioridad» (Superiority Theory), donde, «... we laugh from feelings of superiority over other people»7. Esta teoría dominó la tradición filosófica hasta el siglo dieciocho. La segunda, «La teoría del alivio» (Relief Theory) que «... emerges in the nineteeenth century in the work of Herbert Spencer, where laughter is explained as a release of pent-up nervous energy»». La liberación de energía - como el estrés-, «... provides pleasure because it allegedly economizes upon energy that would ordinarily be used to contain or repress psychic activity» ${ }^{9}$. Finalmente, «La teoría de la incongruencia» (Incongruity theory), donde «... humor is produced by the experience of a felt incongruity between what we know or expect to be the case, and what actually takes place in the joke, gag, jest or blague» ${ }^{10}$. Para este ensayo y el análisis de los poemas, me enfocaré en las teorías de la superioridad y de la incongruencia.

En un estudio claro de lo que es el humor, Critchley comienza señalando que la risa es propiamente del ser humano. Al contrastar al ser humano y los animales, Critchley nos hace ver que el humor marca los límites de aquél. Si volvemos a las teorías mencionadas anteriormente, vemos cómo el humor marca la diferencia entre nosotros los seres humanos que nos sentimos superiores, y los otros animales o seres que percibimos como inferiores. Asimismo, en términos de la teoría de la incongruencia, el humor marca la frontera o el límite entre lo que esperamos y lo que la realidad nos presenta. En este sentido, creo importante comenzar con el análisis de los poemas con la siguiente cita del texto de Critchley:

[...] humour explores what it means to be human by moving back and forth across the frontier that separates humanity from animality, thereby making it unstable, and troubling the hiatus of which Plessner speaks. Humour is precisely the exploration of the break between nature and

\footnotetext{
7 S. Critchley, On Humor, Routledge, Londres y Nueva York, 2002, pág. 2.

${ }^{8}$ S. Critchley, loc. cit.

${ }^{9}$ S. Critchley, loc. cit.

${ }^{10}$ S. Critchley, loc. cit., pág. 3.
} 
culture, which reveals the human to be not so much a category by itself as a negotiation between categories. We might even define the human as a dynamic process produced by a series of identifications and misidentifications with animality. Thus, what makes us laugh is the reduction of the human to the animal or the elevation of the animal to the human ${ }^{11}$.

Como se explica aquí, el humor es un elemento importante para tender un puente entre los seres humanos y los animales -incluyendo los insectos- y guiarnos hacia una reflexión sobre nosotros mismos. En el contexto del análisis de los siguientes poemas de Watanabe, los seres humanos serían los sujetos observantes, mientras los animales serían los objetos observados.

Comenzaré con el análisis del primer poema «La mantis religiosa», que se incluye en el poemario El huso de la palabra. Este poema abre con la mirada del sujeto poético que se desplaza del «bosque azulado por el sol» hasta enforcarse en la matis religosa «que permanecía inmóvil a $50 \mathrm{~cm}$. de $/ \mathrm{mis}$ ojos» ${ }^{12}$. Una vez que el sujeto poético detiene su mirada en el insecto, le entran las ganas de atraparla. Dice: «Quise atraparla, demostrarle que un ojo siempre nos descubre» ${ }^{13}$. Aquí presenciamos cómo el ser humano intenta imponerse; trata de poseer al insecto y de demostrarle que alguien siempre está al acecho. Sin embargo, nos damos cuenta de que es un truco de percepción ya que en el intento la mantis religiosa se desvanece en sus manos: «pero se desintegró entre mis dedos como una fina y quebradiza/cáscara» ${ }^{14}$. Lo que ha tratado de atrapar el sujeto poético es un «macho vacío»; uno que solamente es cáscara ya que le han devorado sus entrañas. En un segundo intento de poseer al insecto, la voz poética acude a una enciclopedia, pidiendo una explicación de lo que acaba de experimentar. Es decir, exige una definición racional de lo que ha presenciado; simbólicamente quiere atrapar al insecto por medio de la palabra y la ciencia. Prosigue entonces a exponernos unos versos en donde se explica el coito de las mantis:

Duradero es el coito de las mantis.

En el beso

Ella desliza una larga lengua tubular hasta el estómago de él

y por la lengua le gotea una saliva cáustica, un ácido que va licuándole los órganos

y el tejido del más distante vericueto interno, mientras le hace gozo, y mientras le hace gozo la lengua lo absorbe, $[\ldots]^{15}$.

Aparte de los detalles de este acto peculiar, como es evidente, en estos versos se ejemplifica la teoría freudiana del eros y thanatos. Mientras le hace el amor

\footnotetext{
${ }^{11}$ S. Critchley, loc. cit., pág. 29.

12 J. Watanabe, Poesía completa, Editorial Pre-Textos, Lima, 2008, pág. 66.

$13 \mathrm{~J}$. Watanabe, loc. cit.

14 J. Watanabe, loc. cit.

${ }^{15} \mathrm{~J}$. Watanabe, loc. cit., págs. 66-67.
} 
el macho, la hembra le absorbe su sustancia y lo deja vacío. Es decir, los dos elementos simbólicos del amor y la muerte se resumen aquí; se trata de la expresión más contundente de la condición humana. Asimismo, se asume una tentativa posesión del insecto por el ser humano en base a la explicación científica y la asociación con el mundo de la psicología. No obstante, el poema, después de conducirnos por esta diminuta pero cruel escena en donde se expresa la ley de la naturaleza, concluye con los siguientes versos llenos de un humor irónico que presume colocarle en boca del macho: «Nosotros no debemos negar la posibilidad de una palabra/de agradecimiento» ${ }^{16}$. Obviamente se trata una alusión al placer del coito. La última palabra, aunque se trate de una suposición, la tiene el mismo «macho vacío».

Este poema nos hace reflexionar sobre los temas del amor, la muerte y la vida, partiendo de la perspectiva de los seres humanos. Sin embargo, en este pequeño cuadro, que a primera vista podría considerarse como muestra de la cruel realidad del mundo natural que finaliza en la muerte, a través de la risa que provocan los versos finales, se convierte en una expresión del amor y la muerte como dos caras de la misma moneda que en el poema se define como una «suprema esquizofrenia» ${ }^{17}$, negando así la superposición de una sobre otra. Al igual, este poema nos muestra las limitaciones en el poder o querer «atrapar» a través de nuestra conciencia y nuestra palabra - me refiero al ser humano- el reino animal. Al ser humano que atestigua la tajante ley de la naturaleza, se le desintegra el objeto que intenta capturar, y al final solamente puede hablar de posibles palabras o suposiciones; esto es, se le escapan las palabras. Aquí vemos que la representación simbólica de la distancia entre lo que concibe y percibe el ser humano y la realidad que se presenta ante él es la risa que provoca el imaginar al macho muerto pronunciando palabras de agradecimiento. Si es que entendemos que Eros, además de ser el dios del amor y la pasión, también representa la fuerza cósmica, entonces podemos interpretar el deseo de la voz poética por integrarse al todo - que representa la naturaleza - y el deseo de trascender. En palabras de Critchley, esto se relaciona a la condición del ser humano ante la naturaleza:

Humour effects a breakage in the bond connecting the human being to its unreflective, everyday existence. In humour, as in anxiety, the world is made strange and unfamiliar to the touch. When I laugh or just smile, I see myself as the outlandish animal that I am, and being to reflect on what I had previously taken for granted. In this sense, humour might be said to be one of the conditions for taking up a critical position with respect to what passes for everyday life, producing a change in our situation which is both liberating and elevating, but also captivating, showing all too clearly the capture of the human being in the nets of nature ${ }^{18}$.

\footnotetext{
16 J. Watanabe, loc. cit., pág 67.

${ }_{17} \mathrm{~J}$. Watanabe, loc. cit.

${ }^{18}$ S. Critchley, op. cit., pág. 41.
} 
Al tratar de imaginar las últimas palabras del «macho vacío», el sujeto poético es presa - contrario a su intención inicial- de las redes de la naturaleza y la risa lo conduce a una reflexión sobre lo extremo en el placer del coito; un éxtasis equiparable solamente con la muerte. En esta esfera, la palabra misma se desintegra. Lo único que queda es suponer o no «... negar la posibilidad de una palabra/de agradecimiento» ${ }^{19}$.

Proseguiremos ahora al análisis del segundo poema titulado «Fábula». El poema es parte del poemario Piedra alada, y nos conduce por una escena cotidiana en un lugar árido y caluroso donde la voz poética es testigo de una yegua que se orina sobre un sapo. Los primeros versos abren con la siguiente observación: «En el cauce del río seco/una espigada yegua orina sobre un sapo agradecido ${ }^{20}$. Inmediatamente se presenta el humor que se puede apreciar en la combinación de elementos contrastantes como serían «orina» y «sapo agradecido». Es decir, uno se imagina una escena graciosa donde el sapo está agradecido que la yegua se orine sobre él. Desde el punto de vista del ser humano que suele posicionarse por encima de los otros animales o insectos al considerarlos como seres inferiores, esta acción, por la risa que provoca, puede analizarse desde la «teoría de la superioridad» que propone Critchley. La risa es producto del pensar que sólo un animal podría no sentir asco por la orina y más bien está agradecido. En cambio, para el ser humano sería imposible concebir tal reacción. No obstante, si cambiamos de perspectiva y entendemos esta escena de acuerdo a las leyes de la naturaleza, hay una razón lógica detrás del «sapo agradecido». Ya que el poema insiste en que se trata de un ambiente seco y árido como lo indica el siguiente verso, «es sólo un poco de agua ácida en esta sequedad solar» ${ }^{21}$, aún cuando se trata de la orina de la yegua, para el sapo es un baño que refresca. Ahora bien, al ver al sapo meado, el sujeto poético trata de racionalizar e interpretar lo que ha atestiguado, recordando la historia del príncipe y el sapo. Nos indica: «... recuerdo una antigua ley de compensaciones de la magia: más feo el sapo más bello y deslumbrante el príncipe»²2. Esto es, trata de minimizar lo que en esencia expone la triste condición del sapo. Una vez que termina con sus necesidades, la yegua se va trotando aliviada y la voz poética concluye con una reflexión en los últimos cuatro versos: «el pobre [sapo] no tenía encantamiento y se quedó solo y soportando su fealdad inmutable y ahora meada ${ }^{23}$. Esta última sentencia provoca, de nuevo, una risa. Se trata de una conclusión irónica que ayuda a que el sujeto poético pueda aceptar su propia condición.

En esta última reflexión por parte de la voz poética, está la clave para entender el poema. En el poema hay dos lógicas: la de la naturaleza donde el sapo agradece por la bendición del baño de orina en un ambiente sofocante, y la del

\footnotetext{
19 J. Watanabe, op. cit., pág. 67.

20 J. Watanabe, loc. cit., pág. 362.

${ }^{21} \mathrm{~J}$. Watanabe, loc. cit.

22 J. Watanabe, loc. cit.

$23 \mathrm{~J}$. Watanabe, loc. cit.
} 
«yo» poético que siente pena por el sapo solo, feo y encima meado. Estas dos lógicas se contraponen y es precisamente en el hiato donde surge el humor. Lo que dicta el mundo natural no coincide con la perspectiva de supuesta superioridad del ser humano que intenta colocarle un valor subjetivo a la escena que ha presenciado. El pobre sapo, como ser inferior, ha sido ridiculizado y no se percata de esto. No obstante, si analizamos los últimos versos con detenimiento, uno se da cuenta de que el sentimiento que esta escena evoca en el ser humano, no es exactamente uno de simpatía. El poema dice:

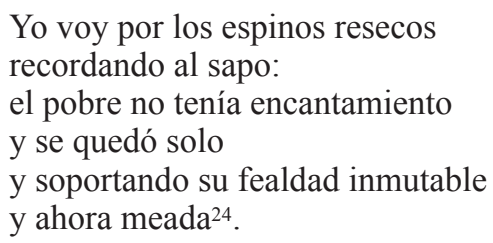

Lo que vemos aquí, más bien es un sentimiento de empatía. El sujeto poético se aleja andando por los «espinos secos» pero marcado por el recuerdo del sapo meado que acaba de presenciar. En esta reflexión podemos entrever una superposición del sujeto y el objeto.

Para entender el verdadero sentimiento de la voz poética, cabe señalar que este poema se puede dividir, esencialmente, en dos escenas. La voz poética va de paso en la primera escena. Es testigo, en ese momento, de la ley de la naturaleza donde presencia al sapo meado. En la segunda escena, hay un proceso de pensamiento y reflexión sobre su propia condición. Cuando la yegua se aleja «trotando y moviendo las ancas como una muchacha» 25 , es cuando comienza la empatía que obliga a la voz poética a verse a sí mismo y reflexionar sobre sí mismo. Es decir, el sapo se vuelve una representación simbólica de él, y la risa que provoca es a la vez una risa de autocrítica; él también está solo, es feo y se encuentra abandonado. En el texto de Critchley se indica que el humor es parte del entenderse uno mismo. Se trata de una autocrítica en donde se contraponen el ego (el yo) y el super-ego (el superyo). Según Critchley, al hacer una comparación entre la depresión y el humor: «Humor has the same formal structure as depression, but it is an anti-depressant that works by the ego finding itself ridiculous $»^{26}$. Asimismo, menciona que $« \ldots$ in humour, we see the profile of 'super-ego II', a super-ego which does not lacerate the ego, but speaks to its words of consolation. This is a positive super-ego that liberates and elevates by allowing the ego to find itself ridiculous $\rangle^{27}$. Partiendo de esta idea por el filósofo inglés en torno a una percepción freudiana del humor, el sentir pena por el sapo y el insistir en su condición desesperante en los últimos

\footnotetext{
24 J. Watanabe, loc. cit.

$25 \mathrm{~J}$. Watanabe, loc. cit.

${ }^{26}$ S. Critchley, op. cit., pág. 101.

${ }_{27}$ S. Critchley, loc. cit., pág. 103.
} 
versos - especialmente cuando dice: «y soportando su fealdad inmutable y ahora meado»- es un humor irónico que ayuda a que el super-ego (superyo) no domine su ego (yo); que la voz poética pueda aceptar su propia condición. En otras palabras se ríe para no llorar, y el sujeto poético se identifica con el sapo meado. Hasta se podría conjeturar que hay un elemento de alivio por parte de la voz poética ya que estamos ante una escena donde otros seres padecen de un infortunio similar, pero lo que los «salva» psicológicamente es que no hay una reflexión sobre su condición. Para el sapo las cosas son como son, pero es el mismo sujeto poético que, al infundirle sentimientos propios a la escena, provoca una risa que a su vez se trata de una ridiculización de sí mismo sufriendo de soledad y falta de amor.

Finalmente tenemos un tercer poema titulado «El camello» que es parte de algunos poemas inéditos que dejó José Watanabe. Se trata de un poema corto de once versos. El poema abre con una escena donde la voz poética está caminando por unas dunas cuando se fija en un camello. La voz poética nos indica que: «la proverbial mirada del camello/es la de un estúpido que nos comprende ${ }^{28}$. En estos versos se establece un contraste: la mirada del camello es «la de un estúpido» pero la del sujeto poético, no. Sin embargo, hay una paradoja; esta «mirada estúpida» dice la voz poética, «nos comprende». Es decir, comprende al ser humano. Inmediatamente después tenemos un verso aislado que dice: «Una mirada insultante»29. Aquí se invierten los papeles. El ser humano —el sujeto poético - ahora se siente amenazado por la «mirada insultante» que «lo comprende»; lo ha delatado. En la tercera estrofa, hay un cambio de tono en donde se le está dando la razón al camello y se pone en duda la interpretación que en un inicio la voz poética le da a la mirada del dromedario. Ahora nos indica que la mirada del camello es: «tal vez razonable». Es decir, basándonos en la teoría de superioridad que propone Critchley, aquí la voz poética va cuestionando la aparente superioridad del ser humano con la que abre el poema. El camello sabe más sobre el desierto y eso lo indica la voz poética diciendo: «porque en medio del desierto/que simplifica nuestros objetivos, pregunto: ¿ ¿para qué nos atrevemos con las inmensidades? $\gg^{30}$. La risa surge inmediatamente después; cuando la respuesta a la pregunta es el silencio del camello. El poema concluye con los siguientes versos: «No hay respuesta/y el sol se pone entre las dos gibas del camello» ${ }^{31}$. Este silencio es tajante; aunque no diga nada lo dice todo. Las palabras en boca del sujeto poético son relegadas a un segundo plano.

Este poema se trata de una visión satírica del hombre en su intento por abarcar y explicar todo. El camello en realidad sabe cuál es la respuesta a la pregunta retórica; hay límites, especialmente cuando hablamos de la inmensidad

\footnotetext{
28 J. Watanabe, op. cit., pág 456.

29 J. Watanabe, loc. cit.

$30 \mathrm{~J}$. Watanabe, loc. cit.

${ }^{31} \mathrm{~J}$. Watanabe, loc. cit.
} 
del desierto. Como se puede apreciar, en este poema se nos invita otra vez a hacer una reflexión sobre la condición del ser humano que sale a relucir por medio del uso de un humor irónico que surge como resultado del intento de enfrentarse a las leyes de la naturaleza. El sujeto poético trata de imponer su superioridad al calificar la mirada del camello como «la de un estúpido». No obstante, poco a poco la voz poética se va achicando para verlo todo reducido al silencio; una pregunta que hace sin respuesta. Al reírnos de esta inversión de papeles, entendemos la relación que se establece entre el «yo» y el todo que representan los elementos de la naturaleza. Esto es evidente en el último verso donde dice: «y el sol se pone entre las dos gibas del camello» ${ }^{32}$. Simbólicamente entendemos que el ser humano no puede imponerse ni puede dominar su entorno. De nueva cuenta, el humor aquí es una autocrítica de la voz poética que, en base a la burla implícita del camello, el cual le responde simplemente con una mirada insultante, le hace saber sobre sus limitaciones y lo calla o más bien lo pone en su lugar, ante su actitud ingenua pretender saberlo todo, de poder abarcarlo todo. Como señala Critchely, «What makes us laugh, I would wager, is the return of the physical into the metaphysical, where the pretended tragical sublimity of the human collapses into a comic ridiculousness which is perhaps more tragic $\rangle^{33}$. En efecto, en este poema presenciamos cómo el ser humano se come sus palabras y se hunde en la ridiculez. El humor nos indica que el ser humano no es superior a la naturaleza sino es solamente una parte - tal vez diminuta - de ésta.

Como se ha podido apreciar a través del análisis detallado de los tres poemas seleccionados, vemos que el humor sirve como un puente que se tiende para expresar las limitaciones del ser humano que se enfrenta a la lógica de las leyes de la naturaleza. Lo que en un principio pareciera como un intento por captar la naturaleza a través del ojo y la palabra, y de esa manera establecer su superioridad, a través de la risa, se invierten los papeles. Las leyes de la naturaleza, en última instancia, se imponen haciendo que la voz poética y el lector entren en un estado de reflexión o meditación. Por medio de las teorías de Critchely sobre el humor, podemos aproximarnos al mundo poético de José Watanabe, compaginando los elementos de la naturaleza, la mirada y la palabra, que son fundamentales. La palabra no llega a abarcar lo que el ojo puede, y asimismo, el ojo no llega a abarcar lo que la naturaleza nos muestra. En los espacios o intersticios se pueden encontrar elementos humorísticos y satíricos que nos hacen reflexionar sobre nuestra condición como simples sujetos que componemos el gran mundo natural. Al final lo que queda es una conjetura; una ausencia de la palabra; y una pequeña sonrisa.

\footnotetext{
32 J. Watanabe, loc. cit.

${ }^{33}$ S. Critchley, op. cit., pág. 43.
} 